\title{
CLÍNICAS DE DIREITO: DINAMIZANDO O ENSINO APRENDIZAGEM NOS CURSOS DE DIREITO
}

\author{
Tiago Felipe Coletti Malosso ${ }^{1}$ \\ Gabriel Ludwig Ventorin dos Santos ${ }^{2}$
}

\section{Resumo:}

Partindo de uma abordagem teórico-reflexiva inspirada no método dedutivo, propõe-se a análise da aplicabilidade das clínicas de direito pelos cursos de Direito, especialmente tendo em conta a realidade das instituições privadas de ensino superior. Delineia os conceitos de metodologia ativa e clínicas de direito e revisando as principais normas estatais que tratam dos cursos de Direito no Brasil. Após levantarem-se as vantagens e ressalvados os riscos mercadológicos, conclui-se pela plena viabilidade de sua utilização que pode provocar efetiva emancipação dos alunos e alunas dos cursos de Direito no Brasil e fortalecimento da cidadania no país.

Palavras-chave: Metodologia ativa. Clínica de Direito. Ensino Jurídico. Instituição de Ensino Superior Privada. Cidadania.

\section{LAW CLINICS: STANDARDIZING TEACHING LEARNING IN LAW COURSES}

\begin{abstract}
:
Starting from a theoretical-reflective approach inspired by the deductive method, it is proposed to analyze the applicability of law clinics for law courses, especially taking into account the reality of private higher education institutions. Outlines the concepts of active methodology and clinical law and reviewing the main state norms that deal with law courses in Brazil. After considering the advantages and the market risks, it is concluded that it is fully feasible, which can lead to the effective emancipation of law students in Brazil and the strengthening of citizenship in the country.
\end{abstract}

Keywords: Active methodology. Law Clinic. Legal Education. Private Higher Education Institution. Citizenship.

\section{1 - Introdução}

\footnotetext{
${ }^{1}$ Graduado em Direito pela Universidade Metodista de Piracicaba. Concluiu o mestrado em Direito pela mesma instituição em 2008, sendo bolsista FAPESP nesse período. Dedica-se à docência e a pesquisa em Direito nas áreas do direito penal, direito processual penal, com especial foco na problemática do direitos fundamentais, tendo artigos científicos publicados neste tema.

Endereço postal: Rua Hugo Beraldo, 115, Torre 1, Apt. 106, Americana/SP, CEP: 13.467-060

Endereço eletrônico: tfcmalosso@hotmail.com

${ }^{2}$ Advogado, Professor Universitário, Coordenador de Prática Jurídica, Mestre em Educação, Pesquisador do HIPE (História da Práxis Educativa Social e Comunitária)

Endereço eletrônico: gabrielventorin@gmail.com

Endereço postal: Rua Sumaré, 193, Apto 204, Parque Universitário, Americana/SP. CEP 13467-696
}

Revista de Pesquisa e Educação Jurídica | e-ISSN: 2525-9636 | Encontro Virtual | v. 6 | n. 2 | 
O presente trabalho tem por objetivo abordar a metodologia ativa denominada clínica de direito como instrumento da formação dos alunos e alunas na graduação em Direito, tendo em conta especialmente a realidade das instituições privadas de ensino superior.

Esta contextualização é fundamental para uma reflexão eficaz sobre o ensino superior, na medida em que é necessário compreender o ator principal deste processo de construção do conhecimento, qual seja, o(a) aluno(a).

Não se pode desprezar a realidade de que os(as) ingressantes nas instituições de ensino privado tiveram toda ou a maior parte de sua formação básica nos bancos do ensino público, portanto, em sua grande maioria, não participaram de uma formação básica de boa qualidade, em que pese a dificuldade de se estabelecer este referencial, mas que principalmente tenha estimulado a criatividade e o interesse pela pesquisa. (OLIVEIRA; ARAÚJO, 2005)

Outro dado palpitante desta realidade é o de tratar-se de estudantes trabalhadores. Os(as) alunos(as) além do compromisso com os estudos são os responsáveis ou participam da responsabilidade de pagar os custos do estudo, além da sobrevivência própria e muitas vezes de sua família.

Associado a estes dados da realidade, verifica-se que a opção pelo curso de Direito por parte dos ingressantes advém da expectativa de alcançar um cargo público, visto primeiramente como a forma de atingir padrão de vida digno para si e para a família, e, se possível, realização profissional.

Além destes aspectos socioeconômicos também existe a realidade cultural dos atuais ingressantes no ensino superior. Tratam-se de pessoas da geração Y e cada vez mais da geração Z, manifestando decrescente capacidade de concentração, sendo cada vez mais refratários a aulas orais expositivas, exigindo abordagens diferentes daquelas largamente utilizadas nos cursos de Direito.

Diante deste cenário, propiciar ao ingressante no ensino superior condições de apreender os elementos necessários ao seu desenvolvimento intelectual tem se mostrado verdadeiro desafio para os profissionais do ensino superior.

A inspiração para uma solução para estas dificuldades pode ser inspirada no pensamento de Paulo Freire ao afirmar que “(...). Só existe saber na invenção, na reinvenção, na busca inquieta, impaciente, permanente, que os homens fazem no mundo, com o mundo e com os outros. Busca esperançosa também.” (FREIRE, 1987, p. 33) 
Para Paulo Freire é conditio sine qua non que o(a) aluno(a) seja envolvido diretamente no processo de construção do conhecimento, tirá-lo da posição de mero "arquivador", no sentido de receptáculo de informação, para participar ativamente do processo, algo que é revolucionário para o ensino no curso de Direito que tem arraigado em sua cultura as aulas expositivas ministradas exclusivamente pelo(a) professor(a).

Ainda na perspectiva do educador, para que o(a) aluno(a) possa ter maior interação com o processo de construção do conhecimento é necessário despertá-lo para a importância do conhecimento que se propõe seja apreendido, utilizando-se de estratégias que o desafiem e se utilizem do conhecimento que o(a) aluno(a) já possui.

A educação é atividade desafiadora e que impõe a responsabilidade ao educador de conduzir seu alunado no acesso não só à informação, mas ao conhecimento integral. Este desafio propõe uma reflexão diuturna sobre como os(as) alunos(as) aprendem, a fim de que técnicas educacionais se aprimorem acompanhando os perfis pessoais (FRAIMAN. 2015).

Neste sentido, vem ganhando espaço nos debates sobre educação no ensino superior as denominadas metodologias ativas que segundo Bastos seriam "processos interativos de conhecimento, análise, estudos, pesquisas e decisões individuais ou coletivas, com a finalidade de encontrar soluções para um problema.” (BASTOS apud BERBEL, 2011, p. 29)

As metodologias ativas se utilizam basicamente da estratégia de formação do conhecimento pela busca da resolução de problemas. São propostas situações problema, reais ou fictícias, em que os(as) alunos(as) precisarão se socorrer dos dados teóricos do conteúdo tratado naquele momento para alcançar a solução.

Uma das virtudes destas metodologias é o fato de se utilizarem da experiência do(a) aluno(a), na medida em que propõem a busca de soluções para situações vivenciadas, experimentadas e sentidas pelo(a) próprio(a) estudante em sua experiência de mundo.

Edgar Dale, desenvolvedor da pirâmide de aprendizagem 'Cone of Experience', em 1946 já apresentava as diferenças que uma metodologia prática poderia trazer ao alunado, potencializando seu aprendizado em até setenta por cento mais que em uma aula unicamente expositiva (DALE apud. PANTANO. 2009)

Para além da assimilação de conhecimentos, as metodologias ativas estimulam a autonomia e a criticidade do indivíduo, pois no processo de pesquisa para a resolução do problema apresentado não permaneceram vinculados a perspectiva do professor sobre o conteúdo estudado, mas estabelecerão sua própria perspectiva. 
A utilização reiterada destas metodologias permitirá ao(a) aluno(a) verificar a importância e o significado do conhecimento teórico, mas não o deixará submetido a ele. Permitirá ao(a) aluno(a) transcender a visão do conhecimento como algo estático e vinculante, para a percepção da teoria como algo dinâmico e em processo de contínua formação. Este é um ponto muito relevante destes métodos, dotar o(a) estudante de autonomia e capacidade crítica em relação ao conhecimento.

Nas palavras de BERBEL, "as metodologias ativas têm o potencial de despertar a curiosidade, à medida que os alunos se inserem na teorização e trazem elementos novos, ainda não considerados nas aulas ou na própria perspectiva do professor”. (2011, p. 28)

Aliás, estes aspectos advindos das metodologias ativas atendem de forma mais eficiente aquilo que é estabelecido como finalidade da educação superior pela Lei de Diretrizes e Bases da Educação - LDB (Lei no 9394/96):

Art. 43. A educação superior tem por finalidade:

I - estimular a criação cultural e o desenvolvimento do espírito científico e do pensamento reflexivo;

II - formar diplomados nas diferentes áreas de conhecimento, aptos para a inserção em setores profissionais e para a participação no desenvolvimento da sociedade brasileira, e colaborar na sua formação contínua;

III - incentivar o trabalho de pesquisa e investigação científica, visando o desenvolvimento da ciência e da tecnologia e da criação e difusão da cultura, e, desse modo, desenvolver o entendimento do homem e do meio em que vive;

IV - promover a divulgação de conhecimentos culturais, científicos e técnicos que constituem patrimônio da humanidade e comunicar o saber através do ensino, de publicações ou de outras formas de comunicação;

$\mathrm{V}$ - suscitar o desejo permanente de aperfeiçoamento cultural e profissional e possibilitar a correspondente concretização, integrando os conhecimentos que vão sendo adquiridos numa estrutura intelectual sistematizadora do conhecimento de cada geração;

VI - estimular o conhecimento dos problemas do mundo presente, em particular os nacionais e regionais, prestar serviços especializados à comunidade e estabelecer com esta uma relação de reciprocidade; VII - promover a extensão, aberta à participação da população, visando à difusão das conquistas e benefícios resultantes da criação cultural e da pesquisa científica e tecnológica geradas na instituição.

Ainda neste sentido, especificamente quanto aos cursos de direito destaquese o artigo $5^{\circ}$ da resolução CNE/CES $N^{\circ} 9$, cujo teor harmônico com a LDB, estabelece três 
eixos principais de formação do aluno de Direito que devem ser cumpridos e são conferidos pelas instituições de controle:

Art. $5^{\circ} \mathrm{O}$ curso de graduação em Direito deverá contemplar, em seu Projeto Pedagógico e em sua Organização Curricular, conteúdos e atividades que atendam aos seguintes eixos interligados de formação:

I - Eixo de Formação Fundamental, tem por objetivo integrar o estudante no campo, estabelecendo as relações do Direito com outras áreas do saber, abrangendo dentre outros, estudos que envolvam conteúdos essenciais sobre Antropologia, Ciência Política, Economia, Ética, Filosofia, História, Psicologia e Sociologia.

II - Eixo de Formação Profissional, abrangendo, além do enfoque dogmático, o conhecimento e a aplicação, observadas as peculiaridades dos diversos ramos do Direito, de qualquer natureza, estudados sistematicamente e contextualizados segundo a evolução da Ciência do Direito e sua aplicação às mudanças sociais, econômicas, políticas e culturais do Brasil e suas relações internacionais, incluindose necessariamente, dentre outros condizentes com o projeto pedagógico, conteúdos essenciais sobre Direito Constitucional, Direito Administrativo, Direito Tributário, Direito Penal, Direito Civil, Direito Empresarial, Direito do Trabalho, Direito Internacional e Direito Processual; (...)

Verificada a finalidade do ensino superior e as vantagens proporcionadas pelas metodologias ativas, pode se encontrar nelas uma alternativa adequada para as condições expostas no início deste item.

Existem várias técnicas de ensino-aprendizagem que apresentam estas características, tais como o diálogo socrático, o método do caso, o PBL, o role play, dentre outros. O presente trabalho abordará as clínicas de direito.

A presente pesquisa caracteriza-se como um estudo teórico-reflexivo inspirado no método dedutivo, propondo-se a análise da aplicabilidade das clínicas de direito pelos cursos de Direito, especialmente tendo em conta a realidade das instituições privadas de ensino superior.

\section{2 - Aspectos históricos}

Vários trabalhos acadêmicos indicam que as primeiras experiências com clínicas de direito surgiram no final do século XIX e início do século XX nos Estados Unidos da América do Norte, sendo que a partir de 1930 passa a ganhar corpo a defesa do estudo clínico e a crítica ao modelo de ensino que até então era desenvolvido. (ALVARES, 2006, 228-229). 
Pode se dizer que as clínicas de direito surgem com o propósito de reformar o modelo de ensino estabelecido naquela época nas faculdades de direito norte americanas. O processo de ensino era restrito ao estudo teórico e baseado na análise de precedentes dos Tribunais, um modelo educacional de transmissão enciclopédica e decorativa dos conteúdos das normas e comentários doutrinários, sendo bem caracterizado pela expressão cunhada por Christopher Columbus Langdell de que "a biblioteca é o laboratório do estudante de direito" (LANDGEL apud FRANK, 1933).

Um dos primeiros e mais citados defensores das clínicas de direito é Jerome Frank, autor do artigo ““Why not a Clinical Lawyer-School?”, publicado em 1933 na Revisa da Universidade da Pensilvânia. Para Frank o contato com a prática do direito era essencial a formação do profissional do direito, sendo que o estudante poderia desenvolver várias habilidades ignoradas pelo método de ensino até então desenvolvido. Segundo Frank:

De este modo, los estudiantes aprenderían a observar el lado humano de la administración de justicia, incluyendo, entre otras cuestiones: a) Cómo el jurado decide un caso. Los factores que cuentan en el juicio por jurados. La poca importancia de las instrucciones del juez en el veredicto. El azar como factor a considerar en el juicio. b) El carácter incierto de los hechos del caso cuando ellos resultan controvertidos. La diferencia entre lo que realmente ocurrió entre las partes, y la versión de los hechos que se presenta ante el juez y el jurado. La importancia trascendente de los hechos del caso. La imposibilidad de anticipar el resultado del juicio antes de que el proceso comience, precisamente en virtud de la importancia de los hechos del caso, las múltiples vicisitudes de la actividad probatoria y la falta de certeza acerca de cómo evaluarán los jurados esa prueba. En tal sentido, los hechos son mucho más relevantes que el derecho invocado en el caso. Los principios y reglas legales son sólo una parte de los argumentos que los abogados utilizarán en su esfuerzo por ganar el caso. c) Cómo los derechos usualmente se sostienen en la mala memoria, en los prejuicios y aun en el perjurio de los testigos. d) Los efectos de la fatiga, la atención, la presión política, la corrupción, la pereza, la conciencia, la paciencia o la impaciencia, los prejuicios o la tolerancia de los jueces, en el resultado de un caso. e) Los métodos usados en negociar contratos y resolver conflictos. f ) Cómo um abogado intenta traducir los deseos del cliente (habitualmente mal expresados) en contratos, documentos o estatutos sociales (FRANK apud ABRAMOVIC, 2006, p. 95)

Este breve resumo espelha que Frank considerava que o estudo do direito não pode desprezar a realidade prática de sua aplicação, o direito é voltado para as relações sociais 
entre os seres humanos e toda a complexidade desta relação, que é instável e multifacetária, não se aprende somente com o estudo teórico, mas demanda o conhecimento de como se dá a relação das partes de um processo, dos sujeitos processuais e o desenvolvimento de uma demanda extrajudicial e judicial.

Esta crítica foi sendo cada vez mais assimilada nos Estados Unidos, culminando com a difusão de clínicas de direito por todo aquele país nos anos de 1.960 e 1.970, promovidas com patrocínio da fundação Ford e estimuladas pela American Bar Association. (ALVAREZ, 2006, 230-231).

Deste breve histórico se podem extrair alguns elementos importantes para se compreender o significado das clínicas de direito, quais sejam, a necessidade de conexão entre teoria e prática e a necessidade de desenvolver habilidades para o exercício das profissões jurídicas.

\section{3 - Conceituação de Clínicas de Direito}

O nome clínica vem tomado de empréstimo dos cursos de medicina e representa exatamente o seu significado etimológico, qual seja, a criação de espaço para o(a) estudante atender casos concretos, envolvendo situações reais.

Carlos Ramos Gonzales apresenta a seguinte definição:

En el contexto de la educación legal podemos definirlo como un método de enseñanza-aprendizaje cuyo objetivo es integrar el aprendizaje doctrinal y teórico, las destrezas de análisis, comunicación y persuasión, al manejo de situaciones conflictivas que pueden ser resueltas por un abogado.(GONZALES, 2006, p.281)

De acordo com este autor o método clínico procura desenvolver no(a) estudante a capacidade de análise, comunicação e persuasão, exigindo além do conhecimento teórico sobre os institutos do direito um conjunto de habilidades práticas para encontrar a solução mais adequada para o caso.

Neste contexto de necessidade de aproximação da teoria formal da prática forense viva é que a proposta das clínicas de direito se pautam e tem verdadeiro brilho.

Não apenas por meio de uma aproximação observadora ou um acompanhamento crítico na posta de espectador de casos concretos, mas o(a) aluno(a) deve ser imerso na realidade do caso e do ambiente do exercício do direito. 
Em termos, a metodologia das chamadas clínica de direito, dado seu embasamento histórico, pauta-se em três aspectos essenciais: A formulação teórica para o caso concreto; o trato com o cliente; os manejos práticos na aplicação das teorias.

Assim, para que se efetivamente possa caracterizar o método das clínicas de direito, atingindo sua finalidade de metodologia ativa de formação mais ampla, o(a) aluno(a) primeiro necessita ter um contato acompanhado do caso concreto, sendo lhe permitido a investigação e, de forma acompanhada, integralização do conteúdo teórico com aquela realidade prática.

Num segundo momento, o(a) aluno(a) deve ser chamado ao caráter primariamente humano da aplicação do direito, que é o trato com a parte. Permitir que o(a) aluno(a) tenha contato direto com o sujeito do direito que está instrumentalizando não só permite o fomento de carisma maior com o exercício profissional, mas, com a devida instrução, acrescerá ao ensino formal o aprendizado no manejo de aspectos práticos e ético-profissionais de suma importância.

A compreensão vivida do significado do sigilo profissional, o trato com o conflito de interesses entre clientes diversos e entre o fato concreto e suas balizas morais, a vivência das dificuldades de comunicação propiciadas pelo linguajar puramente técnico são dificuldades que trarão ao aluno um desenvolvimento impar na sua formação.

Concomitantemente, o manejo prático do caso, é consequência da imposição ao alunado da responsabilidade (partilhada com seus orientadores) nos cuidados do caso concreto. Desde sua organização pessoal para atendimento de prazos e atos processuais do feito acompanhado, até a localização física dos locais de interesse para andamento do feito (cartórios, salas de audiência, centrais administrativas e etc...) são conhecimentos que são permitidos e potencializados pela metodologia das clínicas de direito.

As três frentes das clínicas de direito são premissas já conhecidas e criticadas pelos estudiosos das clínicas de direito, sendo de grande valia a concepção de Christian Courtis:

El primero es el desarrollo de la habilidad de formulación porparte del alumno de una teoría del caso, que requiere articular aspectos teóricos y prácticos: investigación y narración de los hechos, investigación del derecho sustantivo y procesal, evaluación y desarrollo de aspectos probatórios(...)

El segundo es el desarrollo de aspectos prácticos relacionados con el trato con el cliente: la entrevista y el manejo de información personal, aspectos de ética professional (...) 
El tercero es el desarrollo por parte del alumno de destrezas prácticas vinculadas con el manejo del caso: el alumno a cargo del caso debe organizar y actualizar el expediente, redactar escritos, presentarlos ante los tribunales o los órganos administrativos donde tramite la cuestión, concurrir a audiencias, llevar la agenda del caso, documentar los distintos pasos procesales y los resultados obtenidos, comunicarse con el cliente para solicitarle documentación, su firma o su comparecencia, entrenar testigos, etc. Por razones temporales - ya abordaré la cuestión-, es probable que no haya tempo para que el alumno haga todo esto, pero seguramente le tocará enfrentarse con algunas de estas actividades. (COURTIS, 2007, p. 10)

A nós parece que o afastamento de uma formação conteúdista, meramente analítica de conteúdo doutrinário legislativo e uma aproximação de uma formação mais sensível para com a sociedade circundante é premissa já estipulada na Lei de Diretrizes Básicas no Brasil (Lei 9394/96).

\section{4 - Da Dificuldade Estrutural da Clínica de Direito}

Porém, da mesma forma que os caracteres de implantação da metodologia das clínicas de direito fazem-se claras, suas dificuldades também são evidenciadas e podem ser identificadas no contexto brasileiro, oriundo de um pensamento mercadológico explorador da concessão educacional no ensino superior que, voltada para a aferição de lucros, pode afastarse das premissas legais.

Com efeito, em alguns casos a preocupação dos cursos de Direito acaba sendo muito mais voltada para a memorização de conteúdos exigidos pelos concursos e exames a que os(as) alunos(as) irão se submeter ao saírem dos bancos universitários do que o despertar do espírito científico e reflexivo.

Enfim, uma filosofia mercadológica, facilitadora daquilo que seria considerado a vulgarização do conhecimento, a potencialização de uma educação reprodutiva e não reflexiva em clima de semiformação, é o pensamento principal inimigo das metodologias ativas.

Neste diapasão convém destacar a fala de Adorno:

No clima da semiformação, os conteúdos objetivos, coisificados e com caráter de mercadoria da formação cultural, perduram à custa de seu conteúdo de verdade e de suas relações vivas com o sujeito vivo, o 
qual, de certo modo, corresponde à sua definição.”(ADORNO, 1985, p.394-396).

A vivência da situação econômica de um país em desenvolvimento, cenário no qual é necessário balancear os custos de uma educação de qualidade, somados a pressão social deste contexto, para que o aluno seja preparado para aquilo que o mercado espera de profissional podem ser elementos perigosos para uma formação reflexiva e, por que não, humanística.

Os controles exercidos pelos órgãos de classe (Ordem dos Advogados do Brasil) e estatais (Ministério da Educação e Cultura), são fatores que, se bem aplicados, poderiam potencializar a aplicação de métodos voltados a formação humanística e socialmente sensível e, ao mesmo tempo, sem deixar de lado as habilidades exigidas para o emprego e atuação profissional rentável, como é o método das clínicas de direito.

Tudo isso, é claro, dependeria ainda da implantação de políticas públicas que favoreçam a estruturação de um ensino superior consistente com as premissas legais previstas, favorecendo uma atuação docente que permita esse contato tão necessidade do alunado com os casos reais.

\section{5 - As Clínicas de Direito no Ensino Superior brasileiro}

No Brasil há de ser destacado o ensino prático como grande portal de aplicação do método em exposição. Calcado nas premissas legais da própria Lei de Diretrizes Básicas, o método das clínicas de direito encontra fértil terreno na educação superior brasileira, malgrado sua aplicação não atingir seu potencial máximo pelas dificuldades já expostas.

As habilidades e premissas do método das clínicas de direito encontram respaldo normativo, praticamente em toda regulamentação do chamado estágio obrigatório.

Neste diapasão, é de relevância, novamente citar o artigo $5^{\circ}$ da resolução 9 do Conselho Nacional de Educação/Câmara Nacional de Educação Superior:

Art. $5^{\circ} \mathrm{O}$ curso de graduação em Direito deverá contemplar, em seu Projeto Pedagógico e em sua Organização Curricular, conteúdos e atividades que atendam aos seguintes eixos interligados de formação: (...)

III - Eixo de Formação Prática, objetiva a integração entre a prática e os conteúdos teóricos desenvolvidos nos demais Eixos, especialmente nas atividades relacionadas com o Estágio Curricular Supervisionado, Trabalho de Curso e Atividades Complementares.(Grifamos) 
Nota-se, assim, que há imposição expressa da integração prática com os conteúdos teóricos dados em sala, justamente uma das virtudes principais do método proposto.

Em verdade há impulso crescente na utilização de metodologias ativas, que se mostram cada vez mais favorecidas pela crescente necessidade de interação do alunado jovem.

A quebra do paradigma do ensino catedrático dogmático do direito parece estar ainda distante, principalmente considerando fatores externos ao curso de direito, como a necessidade da conscientização do próprio educador para ir além da formatação empírica das aulas e verdadeiramente se emancipando em práticas de inversão de protagonismo com o alunado.

A própria impulsão das atividades metodológicas diversificadas demandam tanto do profissional educador quanto do alunado, uma postura diferenciada, sendo que, principalmente aquele que conduz sua didática deve dominar os aspectos metodológicos a fim de fomentar a quebra da centenária prática das aulas expositivas.

Com a clínica de direito não é diferente, o profissional apto produz dinâmicas aptas a alcançar o objetivo do reflexo prático forense e, assim, finalmente alcançando a almejada proposta de desenvolvimento prático.

Consideremos por um instante que a exigência comum feita pelas universidades, faculdades e centro universitários é de que seus educadores possuam formação em direito, e não em educação, sem descartar ainda tratar-se de metodologia de ensino que, comumente, foge ao cenário no qual o próprio educador foi formado e temos fatores de complicação somatizados.

De outro lado, metodologia da clínica de direito também encontra seu lugar perto de muitas outras formas de ensino não expositivo e que podem fomentar raciocínio crítico, imprescindível para mudar o perfil meramente burocrático de boa parte dos operadores do direito.

O destaque na existência de diversidade de aplicações de metodologias ativas, per si, não deve apresentar óbices ou dificuldades na implantação da metodologia da clínica de direito, mas seria no mínimo inocente acreditar que a clínica de direito é a mais simples de aplicação correta.

Não se pode olvidar a demanda de casos adequados, a disposição de tempo acadêmico atribuído ao docente para que seu preparo seja eficaz e dentro das diretrizes da dinâmica 
básica das clínicas, tudo como sendo fatores complicadores que, diante de um cenário de favorecimento de ensino à distância e no qual a economia invade animosamente a seara educacional, a propositura da metodologia da clínica de direito pode refletir verdadeiro desafio administrativo e pedagógico.

Mesmo sendo fértil terreno para a aplicação do método, este não pode ser considerado único para a aplicação do ensino prático, cujo objetivo, claramente pode ser atingido através de outras metodologias.

De toda forma, considerando premissas de educação emancipadora e de formação completa, as clínicas de direito se apresentam como alternativas desafiadoras mas, especialmente se os casos tratados forem aqueles que versam sobre proteção de interesses comuns e sensíveis a sociedade como um todo, em especial os direitos humanos, pode ser poderoso e eficaz instrumento na formação de uma alunado diferenciado.

\section{1 - Da necessária formação humanística e o impacto dos Núcleos de Prática Jurídica para a metodologia das clínicas de direito.}

Paulo Tought, em seu livro 'Uma questão de caráter - Porque a curiosidade e a determinação podem ser mais importantes que a inteligência' apresenta incontáveis estudos nos quais o caráter e os valores de formação humana, quando atrelados ao ensino permite um rendimento.

Analisando os perfis de formação e, inclusive avaliando a idéia de ensino digital, Nicolas Carr menciona o conceito de 'pessoas panqueca'. Referido e jocoso conceito faz uma crítica ao conhecimento superficial sobre inúmeros assuntos que, desprovidos de raciocínio sem aprofundamento ou críticas acuradas, representa o conhecimento de grande parte da população atual. (CARR, 2012.)

Harvard Daniel Golemanem, de outro lado destacou toda a dificuldade que a geração atual possui na manutenção da atenção, relatando a perda de foco mediano de um leito, hoje, de vinte a quarenta por cento do tempo. (GOLEMAN, 2014, p. 27-33.)

Manter a atenção e o aprofundamento de um conhecimento acabam por serem desafios enfrentados comumente pelos educadores em sala de aula, além de ser uma realidade vivida pelo alunado em geral. 
Considerada uma ciência dogmática com foco em leitura, intepretação e análise normativa, o direito se apresenta em um cenário complicado, considerando os problemas de foco e atenção do alunado.

De igual forma, tratando-se de um ramo da ciência permeado pelos fatos sociais de maior impacto e repercussão, considerando ainda o cenário político social conturbado com frequentes e acirradas disputas de ideologias políticas refratadas sempre sobre a mazela da 'corrupção', a necessidade do trato do conhecimento vinculado a valores, passa a ser ainda mais fundamental.

O ambiente de ensino jurídico vinculado ao carácter humanístico pode ser verdadeiro elemento catalizador de uma formação prática que, em premissa, viabiliza ao mesmo tempo o respeito e acesso aos direitos humanos, domínio técnico e uma formação emancipatória e enriquecida por uma formação humanística.

E de que forma os cursos de direito tangenciam as frentes sociais? Qual frente das instituições de ensino jurídico tem por premissa a vivência da prática do direito por meio do acolhimento social das demandas circundantes?

Ressalvadas iniciativas extraordinárias de mutirões públicos, os Núcleo de Prática Jurídica apresentam-se como verdadeiras portas de interação social e locais que podem direcionar o ensino jurídico de forma a impactar a realidade vivida pelo próprio alunado.

Imbuídos de diversas funções a depender do regimento das instituições de ensino mas, sempre à frente da condução do ensino prático, os Núcleos de Prática Jurídica, seja por meio dos escritórios de assistência judiciária ${ }^{3}$

Pela experimentação dos resultados de seus atos com os atendimentos dos assistidos ou até mesmo para direcionar a formatação de clínicas de direito no acompanhamento de demandas sociais de relevância local, os Núcleos de Prática Jurídica podem ser interessante instrumento para impressão de valores e direcionamento da atuação prática em dinâmicas de clínicas jurídicas.

O atendimento da população carente pode apontar para a instituição de ensino sobre quais as demandas locais que demandam atenção e acompanhamento. Conhecidamente complexas, os desafios da população pobre ou das minorias sociais no alcance de seus direitos fundamentais representam absoluta e real saída para conduzir estudos das clínicas de direito.

\footnotetext{
${ }^{3}$ Atuação forense em prol daqueles que não possuem renda mínima para arcar com custos de advogados particulares, vinculados ao aprendizado prático dos alunos de direito conduzido por supervisores advogados.
}

Revista de Pesquisa e Educação Jurídica | e-ISSN: 2525-9636 | Encontro Virtual | v. 6 | n. 2 | p. 20 - 35 | Jul/Dez. 2020. 
Isto é, considerando a abrangência da população atendida, é no Núcleo de Prática Jurídica que as orientações dadas em sala de aula são harmonizadas com a realidade circundante do curso, e podem ser ferramentas de auxílio, inclusive, aos professores que irão conduzir a demanda da clínica de direito.

Fonte atualíssima de casos jurídicos passíveis de estudos em clínicas de direito, se utilizado para viabilizar e estruturar pessoal competente no acompanhamento do alunado no desempenhar dos estudos em clínicas de direito, o Núcleo de Prática Jurídica pode ser verdadeiro viabilizador da dinâmica.

A pessoalidade e individualidade provinda do valor presença física dos assistidos e relação pessoal entre alunos e população, o atendimento ao público tende a propiciar verdadeira aproximação daqueles com a demanda que será estudada na clínica de direito.

Respeitando as experiências particulares dos alunos, individualizando sua compreensão dos problemas atendidos sob a égide dos conteúdos vistos em sala, em quaisquer áreas jurídicas o Núcleo de Prática Jurídica pode viabilizar um assimilar da realidade ao mesmo tempo em que há conscientização do potencial modificador do aluno de direito enquanto profissional atuante.

O fomento da vivência e das experiências pessoais dos(as) alunos(as) com os eventos estudados é campo que potencializa a metodologia das clínicas e incentiva o acompanhamento do alunado no desenvolver criativo de medidas processuais no caso estudado, ao mesmo tempo que o emancipa com os valores necessários para aprimoramento da sociedade que o circunda.

\section{6 - Considerações Finais}

Considerando o objeto de análise delimitado na introdução deste trabalho, pode se concluir que a clínica de direito pelo seu caráter dinâmico e instigante revela-se adequada ao objetivo de tornar mais eficaz e atraente a construção de conhecimento aos estudantes de direito das gerações $\mathrm{X}$ e $\mathrm{Y}$.

De outro lado, a característica eminentemente empírica do método também pode despertar e incentivar o senso crítico aos estudantes provindos de escolas públicas e de camadas sociais econômica e culturalmente menos favorecidas para tornarem-se mais reflexivas em relação a organização da sociedade em que estão inseridas. 
Ademais, numa perspectiva mais abrangente as clínicas de direito podem favorecer o rompimento com os métodos de transmissão enciclopédica e decorativa das fontes do direito e assim despertar os futuros profissionais para o fato de que o Direito para além de representar as balizas normativas, interfere decisiva e diretamente na vida das pessoas.

Por fim, a utilização das clínicas de direito nos Núcleos de Prática Jurídica, com o atendimento de pessoas socialmente vulneráveis, para além dos ganhos para o ensino aprendizagem na perspectiva individual dos discentes já destacados acima, pode propiciar verdadeiro processo de reflexão sobre a realidade social e conscientização da necessidade de promoção da cidadania.

Necessário ter em conta que para além do domínio dos elementos técnicos necessários à operar o Direito, os futuros profissionais do direito precisam ter a exata percepção do Direito no processo de construção da cidadania no Brasil e que estejam socialmente comprometidos e passem a ser atores para uma sociedade implementadora dos direitos humanos, elementos que a clínica de direitos especialmente trabalhada em Núcleos de Prática Jurídica pode impulsionar com grande efetividade.

\section{7 - Referências Bibliográficas}

ABRAMOVIC, Victor. La enseñanza del derecho em las clínicas legales de interes publico: materiales para uma agenda temática. In: VILLAREAL, Marta; COURTIS, Christian (coord.). Enseñanza Clínica Del Derecho: uma alternativa a los métodos tradicionales de formación de abogados. México: ITAM, 2007. p. 91-121.

ADORNO, Theodor Ludwig Wiesengrund. Educação e Emancipação. Tradução de Wolfgang Leo Maar. Rio de Janeiro: Paz e Terra, 1995.

ÁLVAREZ, Alícia. La educación clínica: hacia la transformación de la enseñanza del derecho. In: VILLAREAL, Marta; COURTIS, Christian (coord.). Enseñanza Clínica Del Derecho: uma alternativa a los métodos tradicionales de formación de abogados. México: ITAM, 2007. p. 225-246.

BERBEL, Neusi Aparecida Navas. As metodologias ativas e a promoção da autonomia de estudantes. Semina: Ciências Sociais e Humanas, Londrina, v. 32, n. 1, p. 25-40, jan./jun. 2011 
CARR.,Nicholas. A geração e seu papel fundamental para o sucesso. Rio de Janeiro:

Objetiva 2014

COURTIS, Christian. La educación clínica como prática transformadora. In: VILLAREAL, Marta; COURTIS, Christian (coord.). Enseñanza Clínica Del Derecho: uma alternativa a los métodos tradicionales de formación de abogados. México: ITAM, 2007. p. 9-24.

FREIRE. Paulo Reglus. Pedagogia da indignação - cartas pedagógicas e outros escritos. São Paulo: Editora Unesp, 2000.

FREIRE, Paulo. Pedagogia do oprimido. São Paulo: Paz e Terra, 1987.

GOLEMAN. Daniel. 'Foco' - A atenção e seu papel fundamental para o sucesso . Rio de Janeiro: Objetiva. 2014

GRAU, Eros Roberto; GUERRA FILHO, Willis Santiago (org.). Direito Constitucional: estudos em homenagem a Paulo Bonavides. . São Paulo, SP: Malheiros, 2001.

OLIVEIRA, Romualdo Portela de; ARAUJO, Gilda Cardoso de. Qualidade do ensino: uma nova dimensão da luta pelo direito à educação. Revista Brasileira de Educação. Jan-abr 2005, $\mathrm{n}^{\mathrm{o}} 28$, p. $5-24$

PANTANO, Telma Zorzi, Jaime Luiz Neurociência aplicada à aprendeizagem - São José dos Campos Pulso. 2009.

TOUGHT, Paulo. Uma questão de caráter - Porque a curiosidade e a determinação podem ser mais importantes que a inteligência’ Rio de Janeiro: Intrínseca. 2014. 